\title{
Young people under youth justice supervision with varying child protection histories: An analysis of group differences.
}

\begin{abstract}
There is now convincing evidence that childhood maltreatment is associated with youth offending; however, relatively little is known about the characteristics and needs of those who are involved in both the child protection and youth justice systems and the extent to which these might differ according to level of child protection involvement. This study reports the characteristics and needs of 2,045 young people who were under supervision in secure custody or detention in South Australia between 1995 and 2012 according to the level of exposure to the child protection system in an Australian jurisdiction. Five groups of young offenders were compared: 1) no known child protection notifications or substantiated experience of abuse and/or neglect; 2) notifications only; 3) substantiated notifications; 4) notifications or substantiations and subsequent placement in out-of-home care (OHC); and 5) placement in OHC only. The results indicate that young people who have a history of child protection system involvement have significantly greater and more complex needs than those who have no child protection experience. It is concluded that different service responses may be required to meet the diverse needs of these groups of young people under youth justice supervision.
\end{abstract}


Despite the well-established link between childhood maltreatment and subsequent youth offending, researchers and policy makers have only recently recognized the need to understand the characteristics of young people who are involved in both the child protection and youth justice systems (Giallella, 2015; Wright, Spohn, Chenane, \& Juliano, 2017). In the review that follows, we provide an overview of conceptual issues and research findings that informed our research into the interplay between variations in child protection history and how they relate to the diverse characteristics and needs of young people under youth justice supervision.

\section{Child Protection Involvement}

It is important to recognize that young people differ in their involvement with child protection systems. For example, some young people are the subject of reports (notifications) to child protection agencies that are not considered serious enough to warrant investigation. For others, an investigation will follow a notification which aims to verify or substantiate an occurrence of either abuse or neglect. When this happens, children who are considered to be too vulnerable to remain living at home may then be placed in out-of-home care (OHC) living arrangements.

On the whole, most previous research has investigated the outcomes of young people for whom maltreatment has been substantiated (see Malvaso, Delfabbro \& Day, 2015 for a review). This line of inquiry aims to establish the causal links between maltreatment and subsequent antisocial behavior. That is, by limiting samples to include only substantiated cases of maltreatment, researchers can be more confident that observed offending outcomes are likely to be a consequence of the maltreatment itself, rather than of other factors, such as poverty, socio-economic status, or educational achievement (Smith, Park, Ireland, Elwyn, \& Thornberry, 2013). However, due to the fact that some types of maltreatment are more likely 
to be substantiated than others (Leiter, Myers, \& Zingraff, 1994), these studies are inevitably biased towards the more severe cases of maltreatment. For example, investigators are required to confirm patterns of failure in supervision or caregiving in order to substantiate incidents of neglect, whereas only a single identifiable incident is required in cases of physical or sexual abuse. On the other hand, data on unsubstantiated cases are more likely to be over-inclusive (i.e., false positive reports of maltreatment), or reflect less serious incidents (Widom, 1988). However, there is evidence from studies such as those reported by both Leiter et al. (1994) and Bright and Jonson-Reid (2008) that young people with unsubstantiated cases of maltreatment are just as likely to be involved in the youth courts as those who have substantiated cases.

Young people who have had their maltreatment substantiated are also more likely to be placed in $\mathrm{OHC}$ or receive other interventions that are intended to ameliorate the consequences of abuse and neglect. However, there is evidence that placement in some forms of $\mathrm{OHC}$ (e.g., residential care or group homes) often exacerbates behavioral problems (Goodkind, Shook, Kim, Pohlig, \& Herring, 2012; Ryan, 2012; Ryan, Hong, Herz, \& Hernandez, 2010; Ryan, Marshall, Herz, \& Hernandez, 2008). Moreover, the negative effects of placement instability or frequent placement changes on offending behavior have been well documented (DeGue \& Widom, 2009; Goodkind et al., 2012; Ryan et al., 2010; Yampolskaya \& Chuang, 2012). Young people can also enter OHC through pathways other than maltreatment, such as when their parents are institutionalized, imprisoned or unable to provide adequate care due to mental health problems. Other studies have also indicated that some young people enter care as a result of behavioral problems (Ryan, 2012; Vinnerljung \& Sallnäs, 2008). This is also an important group to study because it has been reported that those placed due to behavioral problems, or due to a combination of abuse, neglect and 
behavioral issues, are more likely to become involved in offending (Jonson-Reid, 2002; Ryan, 2012; Vinnerljung \& Sallnäs, 2008).

From this overview, it is clear that simple dichotomous categories of child protection involvement do not accurately reflect the varying levels of involvement that children and young people might experience. Although there is potential for numerous comparisons to be made, five different levels of child protection involvement are suggested: 1) no child protection involvement; 2) young people who are only ever the subject of notifications; 3 ) young people with substantiated notifications; 4) young people with notifications or substantiations and who are subsequently placed in $\mathrm{OHC}$; and 5) young people who had been placed in $\mathrm{OHC}$ only (i.e., those placed but without any notifications or substantiations for maltreatment). Comparisons between young people exposed to different levels of child protection involvement can provide deeper insight into the characteristics and needs of these individuals, as well as any differences in the pattern and nature of their offending behavior.

\section{The Crossover between Child Protection and Youth Justice}

Since the majority of existing studies utilize data about community or child protection populations, they typically examine how maltreatment or placement experiences influence the risk of initial involvement with the youth justice system. At the same time, studies that have utilized data held about young offenders do not generally explore associations beyond the prevalence of maltreatment or child protection involvement in these populations (for a review see Wilson et al., 2009). Although a number of recent studies have attempted to elucidate how these experiences are associated with other individual, social and contextual risk factors (see Malvaso, Delfabbro \& Day, 2016 for a review), the characteristics and needs of these young people once they enter the youth justice system are less well understood. 
Other studies have specifically focused on whether children with dual involvement in the child protection and youth justice system, specifically those with OHC backgrounds, (often also referred to as "crossover" children) represent a distinct group of young people who offend (Giallella, 2015; Halemba, Siegel, Lord, \& Zawacki, 2004; Herz \& Ryan, 2007). This group of young people are important to study from a policy and practice perspective given the systemic issues that might contribute to the over-representation of young people with an $\mathrm{OHC}$ background in the youth justice system. For example, research has suggested that these young people are more likely to be subject of disproportionate police attention for behavior that would normally be dealt with by parents in a regular family environment (Cashmore, 2011; McFarlane, 2015). We also know that young people who are involved with OHC backgrounds are often younger at age of first contact with the youth justice system, are less likely to receive probation or be granted bail, and are more likely to be placed in custody on remand (McFarlane, 2010; Ryan, Herz, Hernandez, \& Marshall, 2007). They are also more likely to have higher rates of recidivism (Huang, Ryan, Sappleton, \& Chiu, 2015; Ryan, 2006; van der Put \& de Ruiter, 2016), and worse mental health/behavioral outcomes (Coleman \& Stewart, 2010; Kimonis et al., 2010; Wanklyn, Day, Hart, \& Girard, 2012).

Studies have also demonstrated that, compared to offender-only groups, duallyinvolved youth are more likely to have disadvantaged family backgrounds (characterized by parental criminality, substance abuse and domestic violence; e.g., Malvaso, Delfabbro, Day \& Nobes, in press; Herz, Ryan \& Bilchik, 2010), problems with school and education (suspensions and truancy; e.g., Halemba et al., 2004), and significant mental health (including suicidal ideation and substance abuse issues (e.g., Goodkind et al., 2012; McFarlane, 2017). A number of other studies have also considered the post-traumatic consequences of maltreatment, or trauma and adverse childhood experiences (ACEs) more broadly, among young people who offend (Ford, Chapman, Connor, \& Cruise, 2012; Fox, 
Perez, Cass, Baglivio, \& Epps, 2015; Malvaso, Day, Casey, \& Corrado, 2016). These studies have linked maltreatment to a number of adverse consequences, including depression, anxiety, hopelessness, impulsivity, aggression, and substance misuse.

\section{The Present Study}

To the best of our knowledge there has been no previous attempt to compare the characteristics and needs of young people who offend and who also have had different levels of contact with child protection. Therefore, this study aims to ascertain any differences between the family backgrounds, individual, and social characteristics of young people under youth justice supervision with and without child protection histories. Given the different ways in which contact with the child protection system might occur, five groups of young people under youth justice supervision were compared, These were: Group 1) No history of child protection involvement; Group 2) Notifications only; Group 3) Substantiated notifications; Group 4) Notifications or substantiations and subsequent placement in OHC; and Group 5) placement in $\mathrm{OHC}$ only (i.e., without any notifications or substantiations for maltreatment).

Examining differences between these groups is important for two related reasons. First, children and young people who are most at-risk tend to experience more child protection contact, with those considered at the highest risk often being placed in $\mathrm{OHC}$ and exposed to all of its concomitant risks. Second, involvement in the child protection system itself can be another stressor linked to greater behavioral problems, including offending. Comparing the characteristics and needs of young people in this way can help to identify potential associations between child protection involvement and criminogenic needs among young people who offend. 
Three hypotheses were tested. First, it was predicted that young people under youth justice supervision without child protection histories (Group 1) would have less problematic family backgrounds (including family backgrounds not characterized by criminality or substance abuse) and lower levels of needs than those with any recorded child protection history (including higher scores on measures of intelligence, reading ability, fewer school problems such as suspension or expulsions, and fewer problems with substance misuse, mental health, and behavior), than those with any recorded child protection history (Groups 2-5). Second, young people under youth justice supervision with child protection notifications only and substantiations only (Groups 2 and 3) would have similar family backgrounds and level of need on all factors mentioned above. Third, young people under youth justice supervision with OHC placement backgrounds - regardless of whether they had notifications or not (Groups 4 and 5) would have the most problematic family backgrounds and greatest needs.

\section{Method}

\section{Participants and Procedure}

Data relating to 2,794 young people aged between 10 and 18 who were under youth justice supervision in secure custody or detention arrangements in one Australian jurisdiction between 1995 and 2012 were available for anaysis (hereon referred to as young people under supervision for brevity). During this time, young people under supervision were assessed using an instrument known as the Secure Care Psychological Screening (SECAPS; Putnins, 1999) which recorded background information and information about a range of service needs. For those who were assessed more than once, only the first assessment was used. Official records of youth crime convictions and official child protection records (if any) were then obtained from Youth Justice and Department for Child Protection information systems 
for each young person with a completed SECAPS assessment. The records of child protection system involvement included all notifications and substantiations for abuse and/or neglect, as well as details of any placement in out-of-home care (OHC). To ensure that the full child protection and youth offending histories of individuals in this study were captured, data from a small number of young people under supervision were excluded $(n=30)$ because they had not reached their $18^{\text {th }}$ birthdays at the time of data extraction. Similarly, because child protection records had not become computerized and were not considered reliable prior to 1982, individuals born prior to this date were excluded $(n=719)$. Our final sample included data on 2,045 young people. Data from both databases were then linked using a common numerical identifier. This meant that all data analyzed by the researchers were de-identified.

\section{Measures}

\section{Child Protection Involvement}

As noted above, the level of involvement with the child protection system experienced among young people under supervision was classified according to five groups: Group 1) No child protection histories (referred to as the 'No CP History' group from here on); Group 2) Notifications that were not subsequently substantiated or who had not been placed in OHC ('Notifications Only'); Group 3) Notifications substantiated ('Substantiations Only’); Group 4) Notifications or substantiations and subsequent placement in OHC ('Reports plus Placement'); and Group 5) Placement in OHC but no records of notifications or substantiations ('Placement Only').

\section{Convictions}

Convictions were classified according to the Australian New Zealand Standard Offense Classification (ANZSOC; Australian Bureau of Statistics, 2011 ) and were broken 
down into five main conviction types: violent convictions (included any convictions for homicide, assault, sexual assault and robbery), any non-violent conviction (included any convictions for dangerous or negligent acts endangering persons, abduction or harassment, break and enter, theft, fraud, illicit drugs, prohibited or regulated weapons or explosives, property damage, public order, traffic and vehicle, justice or government, or miscellaneous offenses), property convictions (including any convictions for theft, break and enter, fraud, and property damage), drug-related convictions and breach-related convictions. Reports were also counted as offenses if the matter was proven or agreed on but where no official conviction was recorded (reflecting the commitment to deterrence in the local legislation). However, they were excluded if they were not proceeded with, committed to trial but the defendant was found not guilty, or dismissed.

Age at first conviction was coded as a continuous measure. Number of different types of convictions was determined by counting the number of ANZSOC related offenses an individual was convicted of (maximum possible score was 16). Similarly, number of different violent convictions (maximum possible score was 4), and number of different non-violent convictions (maximum possible score was 12) were also compared.

\section{Measures from the Secure Care Psychological Screening Assessment (SECAPS)}

SECAPS is a standardized assessment instrument based predominantly on self-report. Its purpose was to provide a brief but broad assessment of a variety of factors relating to criminogenic risks and needs, together with risk of self-harm, recidivism and some responsivity factors (such as literacy, numeracy and intelligence). Basic demographic information and family background factors were also collected. The assessments were conducted by youth workers, social worker and psychologists and lasted approximately 30 minutes in duration. Item responses, test scores and assessor comments were into the 
SECAPS electronic database post-assessment. Item selection for examination in this study was based on theory and evidence relating to the crossover between child protection and youth justice as discussed in the introduction of this paper.

\section{Family background and peers}

Family (i.e., parent or sibling) background indicators included several dichotomous variables: parental death; parental separation; family history of crime; family history of substance abuse; household conflict; and mother-child/father-child/stepparent-child relationship. Peer criminality indicated whether or not young people reported having peer who were in trouble with the law.

\section{Individual characteristics and needs}

\section{Intelligence and education}

There were three dichotomous measures of these outcomes: Intellectual ability (scores above borderline on the Raven's progressive matrices; Raven \& Court, 1998); school problems (had dropped out or been suspended/expelled/excluded from school); reading difficulties (scores below 10 on the Australian normed Concision Word Reading Test; Andrews, 1965).

\section{Substance use}

This outcome was classified according to National Health and Medical Research Council guidelines. There were five dichotomous measures: overall substance use (had used alcohol, marijuana, hallucinogens, sedatives, narcotics, stimulants, inhalants or other in the last four weeks prior to assessment); regular drug use (use of any of the above drugs at least once a week during the last six months); drugs by injection (had ever injected drugs); 
problematic alcohol use (consumed three or more drinks on days when drinking); and problematic marijuana use (had one or more smokes on days when using marijuana).

\section{Mental health problems}

Five indicators of mental health problems were used. Current depressive mood was endorsed if the young person self-scored 3 or below on a 10-point scale (where $0=$ worst feeling possible/very depressed and $10=$ best feeling possible/very happy) and chronic depressive mood if the young person (who selected 3 or below on the previous measure) indicated they had been feeling this way for weeks, months or years. Hopelessness was endorsed if a young person responded "agree completely" or "agree a fair bit" to the statement "I feel that I have nothing to look forward to - my future is hopeless". Two measures relating to suicide were included: suicide ideation was endorsed if a young person reported having thoughts of committing suicide in the past week, and suicide attempt was endorsed if a young person reported having tried to kill themself in the past.

\section{Anger and aggression}

Externalizing behavior problems were classified using a dichotomous measures of: anger (endorsed if a young person reported having a bad temper) and aggression (endorsed if a young person reported getting into fights a twice a year or more).

\section{Data Analysis Procedure}

A descriptive overview of the sample is given, followed by comparative analyses aimed at determining differences between the five groups of young people under supervision based on their level of child protection involvement. Chi-square tests of independence were used to compare categorical measures and adjusted standardized residuals used to determine which groups differed significantly from others. As a general rule, residuals greater than 1.96 are indicative of counts higher than would be expected, and residuals less than -1.96 are 
indicative of counts lower than would be expected (Field, 2009). Residuals greater than 1.96 and less than -1.96 were then transformed into chi-square values (which is calculated by multiplying the residual by itself), and the associated p-value was determined using the SIGCHISQ function in SPSS Version 24.0. However, due to the possibility of making a Type I error, a Bonferroni corrected p-value was ascertained by dividing 0.05 by the number of comparison groups (i.e., 5), resulting in an adjusted p-value of 0.01 (Field, 2009). If the pvalue for the new chi-square statistic was equal to or less than the adjusted p-value (0.01), this group value was interpreted as being significantly different from the null hypothesis that the groups would not differ.

Finally, Analysis of Variance (ANOVA) tests were used to determine differences between continuous measures, with the Bonferroni test used for post-hoc comparisons in order to determine which groups were different. 


\section{Results}

\section{Descriptive statistics}

Summary statistics for the sample of young offenders are reported in Table 1.

$<$ Insert Table 1 approximately here $>$

Consistent with national trends, the sample consisted predominantly of males and non-Indigenous youth (AIHW, 2017). Almost seventy-five percent of young people under supervision had some level of contact with the child protection system, with the majority belonging to the Reports Plus Placement group. This is consistent with research that suggests that young people with a history of out-of-home care are over-represented in the youth justice system in Australia (e.g., McFarlane, 2017). Almost a third had at least one conviction for a violent offense. Almost all had at least one non-violent conviction, with property offenses the most common type convicted, followed by breach-related offenses and, finally, drug-related offenses. On average, young people under supervision were convicted of between 1 and 11 different types of crimes prior to the age of 18 , fewer of which were violent than non-violent offenses. The minimum age at first conviction was 10 and the maximum was 18 .

\section{Comparative analysis}

The results of the comparative analyses are reported in Tables 2 (categorical variables) and 3 (continuous variables).

Demographics. Significant associations were found between level of child protection involvement group and both gender and ethnicity. Post-hoc analyses indicated that those in the No CP History group were more likely to include males $(28.3 \%)$ than females $(7.9 \%)$, but that those in the Reports plus Placement group (Group 4) were more likely to include females $(55.7 \%)$ than males $(33.0 \%), x^{2}(4, N=2,045)=85.36, p<.001$. Similarly, post-hoc analyses indicated that that young people in the No CP History group were more likely to include non- 
Indigenous young people (28.1\%) compared to Indigenous $(17.2 \%)$ and that those in the Substantiations Only group were more likely to include Indigenous (15.6\%) compared to non-Indigenous $(9.6 \%), x^{2}(4, N=2,045)=34.76, p<.001$.

Convictions. Significant associations between the level of child protection involvement group and all conviction types were found. Post-hoc analyses indicated that young people under supervision with No CP History group 1 were less likely to have convictions for violent, non-violent, property, and drug offenses as well as breaches of orders (in South Australia, breaches are classified as new offenses although this can differ across jurisdictions). On the other hand, those in the Reports plus Placement group were more likely to have convictions in all categories. Those with in the Substantiations Only group 3 were also more likely to have breach-related convictions.

Significant effects were found for child protection involvement on age at first offense $[\mathrm{F}(4,2038)=86.97, p<.001]$, number of offenses $[\mathrm{F}(4,2040)=31.40, p<.001]$, number of violent offenses $[\mathrm{F}(4,2040)=14.66, p<.001]$, and number of non-violent offenses $[\mathrm{F}(4$, $2040)=25.48, p<.001]$. Post hoc comparisons indicated that those in the No CP History group were older on average than those in the Notifications Only, Substantiations Only, and Reports plus Placement groups, but not significantly older on average than those in the Placement Only group. Furthermore, the Notifications Only group and both the Substantiations Only and Reports plus Placement groups were younger on average than the Placement Only group. Taken together, these results suggest that young people under supervision without a child protection history committed their first offense at an older average age than those who had child protection notifications, substantiations, and those with child protection reports and placement histories, and those with notifications or placement only were older on average at the time of their first offense compared to those with 
substantiations only and those with child protection reports who were subsequently placed in $\mathrm{OHC}$.

For number of offenses, post hoc comparisons indicated that the mean score for the No CP History group was significantly lower compared to all other groups. Furthermore, the mean score for the notifications only group was also significantly lower than the mean scores for the Substantiations Only and reports plus placement groups. For violent offenses, the mean scores for the both the No CP History and Notifications Only groups were significantly lower than the substantiations only, and the former groups mean score was also significantly lower than the mean scores for both the Reports plus Placement and Placement Only groups. Finally, for non-violent offenses, the mean score for the No CP History group was significantly lower than the means scores of all other Child Protection history groups. No other differences were observed.

Family background and peers. Significant associations were found between all variables and level of child protection involvement with the exceptions of parental death and father-child relationship. Post-hoc analyses indicated that, as hypothesized, young people No CP History group were less likely to report parental separation, family criminality, substance use and household conflict. These young people were also less likely to report having poor relationships with their mothers and stepparents. Similarly as hypothesized, those belonging to the Reports plus Placement group had the poorest family backgrounds; these individuals were more likely to report family criminality, substance use, household conflict, and poorer mother-child relationships. With the exception of family criminality, those in the Notifications Only and Substantiations Only groups had similar family backgrounds as hypothesized. Peer criminality was not consistent with any of our hypotheses: young people in the Notifications Only and Placement Only groups were more likely to report associating 
with deviant peers, whereas those in the Reports plus Placement group reported that they did not associate with deviant peers.

Individuals characteristics and needs. In terms of intelligence and education, those in the No CP Sistory group were less likely to score below the borderline ranges for possible intellectual disability and to have reading difficulties. There were no other differences between the groups in terms of intellectual ability, although those in the reports plus placement group were more likely to score below the borderline ranges (this only approached significance, $p=.02$ ). Furthermore, these individuals were more likely to have difficulties reading.

Although there was a significant association between overall drug use and child protection involvement, the standardized residuals were not significant at the $p<.01$ level. However, for regular drug use, it was found that those in the Notifications Only group 2 were more likely to report using drugs regularly, whereas those from both of the $\mathrm{OHC}$ placement groups (Reports plus Placement and Placement Only) were less likely to report using drugs regularly. On the other hand, young people from all three of these groups were more likely to report injecting drugs, whereas those in the substantiations only group were less likely to report injecting drugs. Contrary to our hypothesis, young people in in the No CP History and Notifications Only groups were more likely to report problems with alcohol use, whereas those in Substantiations Only and Reports plus Placement groups were less likely to report problems with alcohol.

Similar to overall drug use, although the association between current depressive mood and child protection exposure was significant, the residuals were not (at the $p<.01$ level). As hypothesized, those in the No CP History group scored lower on the chronic depression and hopelessness measures, and were less likely to report suicidal ideations or attempts. Those in 
Reports plus Placement group 3 scored higher on the depression and hopelessness measures and were more likely to report suicide ideations and attempts.

Finally, whereas young people in the No CP History group were less likely to report having anger problems, those in Substantiations Only group were more likely to report having anger problems.

Further analyses were conducted to determine whether there were any other significant differences between the groups with child protection histories that could also aid in interpreting the above findings. Group 2, 3 and 4 (notifications only, substantiations only, and reports plus placement groups) were compared in terms of total number of notifications (including number for physical, sexual, and emotional abuse, and neglect), substantiations and placement characteristics. Significant effects were found for all categories, except for substantiations, for which the Substantiations Only and the Reports plus Placement groups did not differ in terms of the mean number of substantiations. Those in the Substantiations Only and Reports plus Placement groups had a higher mean number of notifications and were younger at the time of their first notification compared to those with notifications only, $[\mathrm{F}(2$, $1452)=108.33, p<.001$ and $\mathrm{F}(2,1444)=151.90, p<.001$, respectively]. These groups were also more likely to have a higher mean number of notifications in three categories: physical abuse $[\mathrm{F}(2,1424)=76.58, p<.001]$; emotional abuse $[\mathrm{F}(2,1424)=35.44, p<.001]$; and neglect $[\mathrm{F}(2,1424)=52.60, p<.001]$. Those in the Reports plus Placement group 4 were also more likely to have a higher mean number of sexual abuse notifications compared to the two other groups, $[\mathrm{F}(2,1424)=37.27, p<.001]$. Furthermore, those in Reports plus Placement group were younger when they were first placed into care $[\mathrm{t}(96.24)=8.98, p<.001]$, spent a longer period of time in care $[\mathrm{t}(105.82)=4.40, p<.001]$, and had a higher mean number of placement changes $[\mathrm{t}(223.97)=11.41, p<.001]$ compared to those in the Placement Only group. 


\section{Discussion}

This study aimed to ascertain differences between the characteristics and needs of young people under youth justice supervision who had different levels of child protection system involvement. To the best of our knowledge, a comparison of this nature has not previously been made between these subgroups of young people who offend. Consistent with the first hypothesis, it was found that those without a history of child protection involvement had generally less complex family backgrounds and lower levels of needs than those who had a history of child protection. Our second hypothesis was that those with notifications only and substantiations only would have similar characteristics and needs, but this was only partially supported. Similarly, although the two placement groups (Reports plus Placement and Placement Only) were similar in some respects, overall, the third hypothesis - that these groups would have the most complex family backgrounds and greatest needs - was only partially supported because those in the Reports plus Placement group appeared to have the greatest needs.

\section{Family background and peers}

The complex family backgrounds identified among young people under supervision with child protection histories warrants specific discussion given that often these are the reasons young people come to the attention of child protection authorities. Those who were the subject of notifications for maltreatment who were then placed in $\mathrm{OHC}$ had accumulated the greatest number of familial risk factors, including parental criminality and problematic substance use, as well as experiencing household conflict. These individuals were also more likely to have poorer relationships with their mothers. One of the most well established consequences of maltreatment is the disruption caused to primary attachment bonds, such as that between mother and child (Cook et al., 2005). This is thought to be especially disrupted for those who are removed from abusive environments and placed in $\mathrm{OHC}$, often resulting in 
problems in emotion regulation and impulse which can then develop into aggressive or hyperactive behavior or conduct disorders (Ford et al., 2009; van der Kolk \& Fisler, 1994). These problems may be exacerbated if children are not placed with warm and patient carers who are able to model and encourage effective emotion regulation strategies.

There is also evidence that maltreated young people are more likely to associate with similar-minded peers who play a role in reinforcing antisocial beliefs and attitudes (Finkelhor, Ormrod, \& Turner, 2007). However, it was found that only those in the notifications and placements only groups, that is, two of the groups without any substantiated history of abuse or neglect were more likely to report associations with negative peers. It might be that these young people have stronger ties or deeper, long-lasting connections with other young people from their home environment or community. Those who are notified but never placed are likely to remain in sub-optimum environments in which they gravitate towards like-minded peers. Those without any reports for maltreatment who enter care tend to do so at an older age (a finding also confirmed in this study) and might be more likely to remain associated with peer networks that were established prior to placement.

\section{Individual characteristics and needs}

Focusing on education among young offenders with histories of maltreatment could have the potential to influence the direction of offending behavior towards a more positive trajectory. The higher intelligence test scores and better educational outcomes found among individuals without a child protection history suggest that learning and educational abilities might be further compounded by maltreatment and placement in OHC. As noted by Smith et al. (2013), although there has been considerable policy interest in improving academic outcomes for children and young people more broadly, the potential for education to mitigate consequences of maltreatment has not been emphasized. Indeed, there is some evidence that 
suggests that education factors might mediate the relationship between maltreatment and offending in early adulthood (Topitzes, Mersky, \& Reynolds, 2011).

Drug and alcohol problems of some degree were found among all groups of young people in this study, indicating that treatment for these issues is relevant across the broader population of young people under supervision. However, when considering the drug and alcohol factors explored as a whole, it appeared that those in the notifications only group had accumulated problems in most categories, including using drugs regularly, injecting drugs and problematic alcohol use. It might be that those who were only the subject of notifications were more likely to remain in problematic and potentially abusive or neglectful home environments and were therefore more likely to develop maladaptive coping mechanisms such as drug and alcohol use. On the other hand, those in the substantiations only group were less likely to report injecting drugs or having problems with alcohol. It might be that this group, as a result of having their maltreatment verified, was the subject of interventions, such as in-home services, with potentially protective effects.

Although there were no differences between the groups in terms of current depressive mood, individuals who were the subject of child protection reports and were subsequently placed in $\mathrm{OHC}$ were more likely to report chronic depression, hopelessness, suicide ideation and attempts, and anger problems. It has been suggested that traumatized individuals are more likely to perceive situations as threatening, activating fear and flight or anger and fight reactions that are biologically predisposed (Chemtob et al., 1997). Others have suggested that anger following trauma represents a psychological defense mechanism similar to emotional avoidance (Foa et al., 1995). Reacting to a situation angrily or aggressively might be seen as a way of coping or defending oneself but ultimately stems from post-traumatic experiences (Ford et al., 2010). These results suggest that although services to help manage depression are 
relevant to all young people under supervision, particular attention should be paid to victims of maltreatment who might be dealing with longer-term or more intense symptoms.

\section{Offense characteristics}

This study also highlighted that offense characteristics differ among groups of young people under youth justice supervision with and without child protection backgrounds. In terms of age at first offense, those who were the subject of child protection substantiations, as well as those who were the subject of reports and were subsequently placed in $\mathrm{OHC}$, committed their first offense at a younger age than those in the other groups. Similarly, young people in these groups were the most diverse offenders (in terms of number of different types of offenses committed). Although those with notifications were older at the time of their first offense, they were still significantly younger than those without any child protection histories. These findings are consistent with the results of a number of other studies (Malvaso \& Delfabbro, 2015; Rivera \& Widom, 1990; Ryan et al., 2007) and are important because those who start offending early are more likely to commit violence offenses and enter the adult criminal justice system (Burns et al., 2003; Maxfield, Weiler, \& Widom, 2000). Indeed, those in the two placement groups and the substantiations only group also had a higher mean number of violent offenses. This finding was interesting for a second reason. Those in the placement only group were also older at the age of their first offense and might represent a group of young offenders who have a later onset but commit more serious violent offenses. Individuals in this group also entered care for the first time at a significantly later age. It has been suggested that those who are older when they enter care are more likely to be placed due to emotional or behavioral issues (Delfabbro, Barber, \& Cooper, 2001; Farmer, 1996), which might also explain the increased number of violent offenses. 


\section{Limitations and future research}

This study was not without limitations. It is known, for example, that not all instances of maltreatment come to the attention of child protection authorities. In using official records, it is possible that the child protection cases that were identified only represent the more severe cases. In addition, it might be that those classified as not having a child protection history might have still experienced maltreatment. It is also possible that these individuals had child protection histories recorded in other states of Australia that would not have been picked up in South Australian records if they had previously migrated to the state prior to entering secure care. In terms of offending behavior, this dataset only includes young people under supervision in secure custody and detention and does not include those serving community or bail orders or participating in diversion programs. Future research should also consider how child protection histories might influence the characteristics or needs of individuals in these contexts. The study was predominantly exploratory and the design was cross-sectional, therefore causal inferences are limited. Finally, it was not possible to determine concurrent child protection and youth justice involvement in this study. That is, we were unable to identify those young people in detention who had open or ongoing child protection investigations or were under concurrent care and protection orders. Some studies have suggested that individuals with simultaneous involvement in both systems represent a distinct group with greater needs (Giallella, 2015). Therefore, it is not only important for practitioners and policy makers to consider the child protection histories of detainees, but whether the involvement with child protection is current or historical.

Although this study extends previous research by investigating differences among multiple groups with varying levels of child protection exposure, these analyses are preliminary and further research is required to gain a deeper understanding of the unique service needs of these groups. For example, given that the child protection involvement 
groups differed in terms of gender and ethnic composition, separate analyses for males and females, or young offenders with different ethnic backgrounds, might produce further insight into the specific needs of these groups.

\section{Conclusion}

Overall, the results of this study demonstrate the greater and more complex needs of young people with child protection backgrounds under youth justice supervision in South Australia. Although we cannot be sure that these results will generalize to the wider offending population, they do point to the need to consider how different levels of child protection involvement might influence the specific needs of young people in these settings. Alternatively, it may suggest differences in the types of young people who receive different levels of responses from the $\mathrm{CP}$ system and that this is in itself a risk factor for subsequent offending. This information is important for informing the planning and provision of services for young people under youth justice supervision. 


\section{References}

Australian Bureau of Statistics. (2011). Australian and New Zealand Standard Offence Classification (ANZSOC). Canberra: Australian Bureau of Statistics.

Australian Institute of Health and Welfare. (2017). Youth Justice in Australia: 2015-16. Canberra: AIHW.

Bright, C. L., \& Jonson-Reid, M. (2008). Onset of juvenile court involvement: Exploring gender-specific associations with maltreatment and poverty. Child Youth Services Review, 30(8), 914-927. doi: 10.1016/j.childyouth.2007.11.015

Burns, B. J., Howell, J. C., Wiig, J. K., Augimeri, L. K., Welsh, B. C., Loeber, R., \& Petechuk, D. (2003). Treatment, services, and intervention programs for child delinquents. Washington, D.C.: U.S. Department of Justice, Office of Justice Programs, Office of Juvenile Justice and Delinquency Prevention.

Cashmore, J. (2011). The link between child maltreatment and adolescent offending: Systems neglect of adolescents. Family Matters, 89, 31-41.

Coleman, D., \& Stewart, L. M. (2010). Prevalence and impact of childhood maltreatment in incarcerated youth. American Journal of Orthopsychiatry, 80(3), 343-349. doi: 10.1111/j.1939-0025.2010.01038.x

DeGue, S., \& Widom, C. S. (2009). Does out-of-home placement mediate the relationship between child maltreatment and adult criminality? Child Maltreatment, 14(4), 344355. doi: $10.1177 / 1077559509332264$

Delfabbro, P., Barber, J. G., \& Cooper, L. (2001). Children entering out-of-home care in South Australia: Baseline analyses for a 3-year longitudinal study. Children and Youth Services Review, 23, 865-891.

Farmer, E. (1996). Family reunification with hgih risk children: Lessons from research. Children and Youth Services Review, 18(403-418).

Field, A. (2009). Discovering statistics using SPSS. London: Sage Publications.

Finkelhor, D., Ormrod, R., \& Turner, H. (2007). Poly-victimization: A neglected component in child victimization trauma. Child Abuse \& Neglect, 31, 7-26.

Ford, J. D., Chapman, J., Connor, D. F., \& Cruise, K. R. (2012). Complex trauma and aggression in secure juvenile justice settings. Criminal Justice and Behavior, 39(6), 694-724.

Fox, B. H., Perez, N., Cass, E., Baglivio, M. T., \& Epps, N. (2015). Trauma changes everything: examining the relationship between adverse childhood experiences and serious, violent and chronic juvenile offenders. Child Abuse \& Neglect, 46, 163-173. doi: 10.1016/j.chiabu.2015.01.011

Giallella, C. (2015). Are crossover youth a distinct group? Comparing the mental health and substance use needs of crossover youth and delinquent-only youth. (Doctor of Philosophy), Drexel University, Philadelphia.

Goodkind, S., Shook, J. J., Kim, K. H., Pohlig, R. T., \& Herring, D. J. (2012). From child welfare to juvenile justice: Race, gender, and system experiences. Youth Violence and Juvenile Justice. doi: 10.1177/1541204012463409

Halemba, G. J., Siegel, G. L., Lord, R. D., \& Zawacki, S. (2004). Arizona dual jurisdiction study: Final report. Pittsburgh, PA: National Center for Juvenile Justice.

Herz, B., Ryan, J. P., \& Bilchik, S. (2010). Challenges facing crossover youth: An examination of juvenile justice decision making and recidivism. Family Court Review, 48, 305-321.

Herz, D., \& Ryan, J. (2007). Exploring the characteristics and outcomes of 241.1 youth crossing over from dependency to delinquency in Los Angeles county. . San 
Francisco, CA: Judicial Council of California Administrative Office of the Courts, Center for Families, Children, \& the Courts.

Huang, H., Ryan, J. P., Sappleton, A., \& Chiu, Y.-L. (2015). Crossover youth post arrest: Placement status and recidivism. Children and Youth Services Review, 57, 193-200. doi: 10.1016/j.childyouth.2015.08.015

Jonson-Reid, M. (2002). Exploring the relationship between child welfare intervention and juvenile corrections involvement. American Journal of Orthopsychiatry, 72(4), 559576. doi: 10.1037//0002-9432.72.4.559

Kimonis, E. R., Skeem, J. L., Edens, J. F., Douglas, K. S., Lilienfeld, S. O., \& Poythress, N. G. (2010). Suicidal and criminal behavior among female offenders: The role of abuse and psychopathology. Journal of Personality Disorders, 24(5), 581-609.

Leiter, J., Myers, K. A., \& Zingraff, M. T. (1994). Substantiated and unsubstantiated cases of child maltreatment: Do their consequences differ? Social Work Research, 18(2), 6782.

Malvaso, C. G., Day, A., Casey, S., \& Corrado, R. R. (2016). Young offenders, maltreatment, and trauma: A pilot study. Psychiatry, Psychology and Law, 1-12.

Malvaso, C. G., \& Delfabbro, P. (2015). Offending behaviour among young people with complex needs in the Australian out-of-home care system. Journal of Child and Family Studies, 24(12), 3561-3569.

Malvaso, C. G., Delfabbro, P., \& Day, A. (2015). The maltreatment-offending association: A systematic review of the methodological features of prospective and longitudinal studies. Trauma, Violence, \& Abuse, 1-15. doi: 10.1177/1524838015620820

Malvaso, C. G., Delfabbro, P., \& Day, A. (2016). Risk factors that influence the maltreatment-offending association: A systematic review of prospective and longitudinal studies. Aggression \& Violent Behavior, 1-15. doi: 10.1016/j.avb.2016.06.006

Maxfield, M. G., Weiler, B. L., \& Widom, C. S. (2000). Comparing self-reports and official records of arrests. Journal of Quantitative Criminology, 16(1), 87-110.

McFarlane, K. (2010). From care to custody: Young women in out-of-home care in the criminal justice system. Current Issues in Criminal Justice, 22(2), 345-353.

McFarlane, K. (2015). Care-criminalisation: The involvement of children in out-of-home care in the NSW criminal justice system. (Doctoral dissertation), University of New South Wales.

McFarlane, K. (2017). Care-criminalisation: The involvement of children in out-of-home care in the New South Wales criminal justice system. Australian \& New Zealand Journal of Criminology, 1-22. doi: 10.1177/0004865817723954

Raven, J., \& Court, J. (1998). Raven's prohressive matrices and vocabulary scales. Oxford, UK: Oxford Psychologists Press.

Rivera, B., \& Widom, C. S. (1990). Childhood victimization and violent offending. Violence and Victims, 5(1), 19-35.

Ryan, J. (2006). Dependent Youth in Juvenile Justice: Do Positive Peer Culture Programs Work for Victims of Child Maltreatment? Research on Social Work Practice, 16(5), 511-519. doi: 10.1177/1049731506288458

Ryan, J. (2012). Substitute care in child welfare and the risk of arrest: Does the reason for placement matter? Child Maltreatment, 17(2), 164-171. doi: $10.1177 / 1077559512443125$

Ryan, J., Herz, D., Hernandez, P. M., \& Marshall, J. M. (2007). Maltreatment and delinquency: Investigating child welfare bias in juvenile justice processing. Children and Youth Services Review, 29(8), 1035-1050. doi: 10.1016/j.childyouth.2007.04.002 
Ryan, J., Hong, J. S., Herz, D., \& Hernandez, P. M. (2010). Kinship foster care and the risk of juvenile delinquency. Children and Youth Services Review, 32(12), 1823-1830. doi: 10.1016/j.childyouth.2010.08.003

Ryan, J., Marshall, J. M., Herz, D., \& Hernandez, P. M. (2008). Juvenile delinquency in child welfare: Investigating group home effects. Children and Youth Services Review, 30(9), 1088-1099. doi: 10.1016/j.childyouth.2008.02.004

Smith, C. A., Park, A., Ireland, T. O., Elwyn, L., \& Thornberry, T. P. (2013). Long-term outcomes of young adults exposed to maltreatment: The role of educational experiences in promoting resilience to crime and violence in early adulthood. Journal of Interperssonal Violence, 28(1), 121-156. doi: 10.1177/0886260512448845

Topitzes, J., Mersky, J. P., \& Reynolds, A. J. (2011). Child maltreatment and offending behavior: gender-specific effects and pathways. Criminal Justice and Behavior, 38(5), 492-510. doi: 10.1177/0093854811398578

van der Put, C. E., \& de Ruiter, C. (2016). Child maltreatment victimization by type in relation to criminal recidivism in juvenile offenders. BMC Psychiatry, 16, 24. doi: 10.1186/s12888-016-0731-y

Vinnerljung, B., \& Sallnäs, M. (2008). Into adulthood: A follow-up study of 718 young people who were placed in out-of-home care during their teens. Child \& Family Social Work, 13(2), 144-155. doi: 10.1111/j.1365-2206.2007.00527.x

Wanklyn, S. G., Day, D. M., Hart, T. A., \& Girard, T. A. (2012). Cumulative childhood maltreatment and depression among incarcerated youth: Impulsivity and hopelessness as potential intervening variables. Child Maltreatment, 17(4), 306-317. doi: $10.1177 / 1077559512466956$

Widom, C. S. (1988). Sampling biases and implications for child abuse research. American Journal of Orthopsychiatry, 59, 355-367.

Wilson, H. W., Stover, C. S., \& Berkowitz, S. J. (2009). The relationship between childhood violence exposure and juvenile antisocial behavior: a meta-analytic review. Journal of Child Psychology and Psychiatry, 50(7), 769-779. doi: 10.1111/j.14697610.2008.01974.x

Wright, E., Spohn, R., Chenane, J., \& Juliano, N. (2017). The importance of interagency collaboration for crossover youth: A research note. Youth Violence and Juvenile Justice, 15(4), 481-491.

Yampolskaya, S., \& Chuang, E. (2012). Effects of mental health disorders on the risk of juvenile justice system involvement and recidivism among children placed in out-ofhome care. American Journal of Orthopsychiatry, 82(4), 585-593. doi:

10.1111/j.1939-0025.2012.01184.x 